\title{
Second observation of Dermatemys mawii in the upper Yucatán peninsula: a new population or an old individual?
}

\author{
JOHN DAVID CURLIS*, MOLLY A. HIRST \& MARCELLA D. BAIZ
}

University of Michigan, Ann Arbor, Michigan, USA

${ }^{*}$ Corresponding author e-mail: curlisjd@umich.edu

$T_{\text {or }}^{\text {he }}$ he Central American river turtle (Dermatemys mawii), or hickatee as it is known in Belize (Briggs-Gonzalez et al., 2018), is a large, freshwater turtle that represents the last remaining lineage of the family Dermatemydidae (Iverson \& Mittermeier, 1980). Historically, this species was widely distributed throughout southern Mexico, Belize, and northern Guatemala (Alvarez del Toro et al., 1979; Iverson, 1992; Ernst \& Barbour, 1989; Iverson \& Mittermeier, 1980; Lee, 1996; Legler \& Vogt, 2013; Vogt et al., 2011; BriggsGonzalez et al., 2018). However, due to harvesting for meat consumption (Moll, 1986; Polisar, 1994, 1995), numbers have declined drastically throughout much of its range, leading to its designation as a critically endangered species (Vogt et al., 2006; IUCN, 2019). The current distribution and many aspects of the general biology and life history of this turtle are not well known (Briggs-Gonzalez et al., 2018).

Dermatemys mawii was first reported from the northern coast of the Yucatan peninsula $\left(21.281111^{\circ} \mathrm{N}, 89.643056^{\circ} \mathrm{W}\right)$ on 30 April 2010 (Chablé-Santos et al., 2011). This represented a $239 \mathrm{~km}$ northerly range extension for the species, although the specimen was presumed to be introduced (Vogt et al., 2011). Herein we document a second observation of D. mawii along the northern coast of the Yucatán Peninsula. On 6 March 2019, while hiking through La Reserva Ecológica El Corchito in the municipality of Progreso, Yucatán, Mexico $\left(21.274754^{\circ} \mathrm{N}\right.$, $\left.89.645159^{\circ} \mathrm{W}\right)$, we encountered and photographed an adult Dermatemys floating and swimming in the center of a cenote surrounded by mangroves and creeks (Fig. 1). This observation was made at a distance of roughly 740 m away from the 2010 record. It suggests either that more than one individual is present in the area or that we encountered the same individual as Chablé-Santos et al. (2011) nearly nine years later.

We attempted to determine whether the individual we encountered was the same as that in 2010 by referencing photographs of the two specimens. Both individuals appeared to be adult females, as indicated by the lack of yellow on the top of the head (Rainwater et al., 2012). The individual from 2010 was captured and marked with blue wire on the left supracaudal scute for identification at a distance (Fig. 2). While the individual in 2019 did not have this marking, it did have a conspicuous notch in the carapace where the wire would have been. As such, it may be impossible to determine whether the photographed individuals are different or if the individual from 2010 had simply lost the marking over the years.

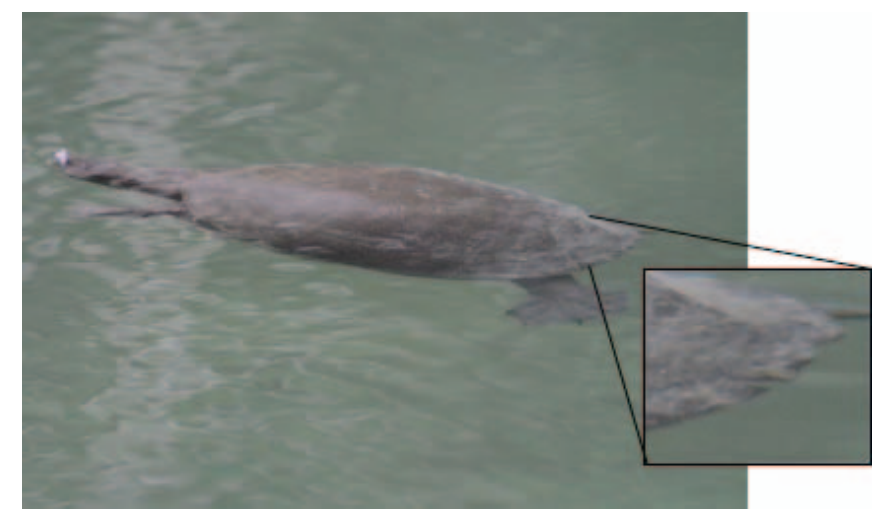

Figure 1. Adult female $D$. mawii observed in a freshwater cenote in 2019. Note the deep notch in supracaudal scute (inset).

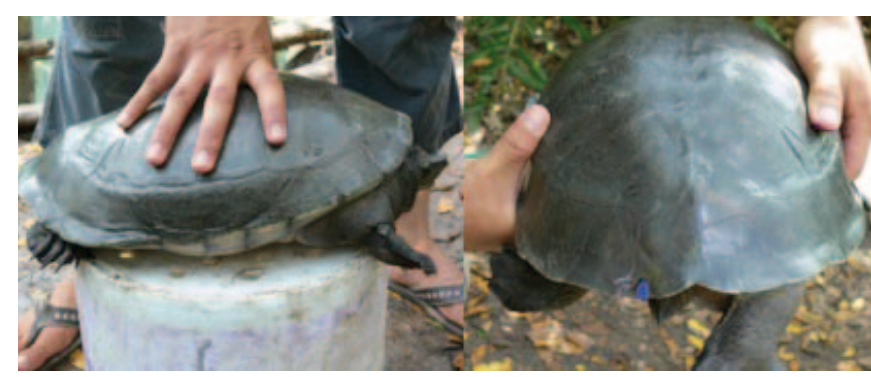

Figure 2. Adult female D. mawii found in 2010 and marked with blue wire. Photos courtesy of Juan B. Chablé-Santos.

Regardless of whether the 2019 and 2010 observations represent one or two individuals, the current sighting has important implications for the conservation of Dermatemys. If the same individual was indeed observed nine years apart, then, given that the individual observed in 2010 was already an adult (Chablé-Santos et al., 2011), this would suggest that the longevity of adult Dermatemys in the wild is at least nine years. It may also imply that La Reserva Ecológica El Corchito is a suitable habitat for this species to thrive. If, in contrast, the two observations represent two different turtles, then this may indicate the establishment of a population in the El Corchito area. Identifying localities in which Dermatemys may persist, or are already persisting, could prove critical for conservation plans and potential head-starting or reintroduction programmes. We stress the need for further investigation into La Reserva Ecológica El Corchito and the surrounding areas (the home ranges of most aquatic turtles 
are within a few square kilometers at most (Slavenko et al., 2015)) in order to determine which of the two scenarios proposed for our observation is more likely, as well as to lend insight into what factors might contribute to the apparent suitability of this habitat that is so distant from the primary range of this species.

\section{ACKNOWLEDGEMENTS}

We thank Juan B. Chablé-Santos for providing information and photos regarding the 2010 Dermatemys record. We also thank Grover Brown for confirming our species identification and for helping to direct us to relevant information, publications, and maps concerning Dermatemys.

\section{REFERENCES}

Alvarez del Toro, M., Mittermeier, R. A. \& Iverson, J.B. (1979). River turtle in danger. Oryx 15: 170-173.

Briggs-Gonzalez, V., Gonzalez, S. C., Smith, D., Allen, K., Rainwater, T. R. \& Mazzotti, F. J. (2018). Dermatemys mawii (the hicatee, tortuga blanca, or Central American river turtle): A working bibliography. Caribbean Naturalist 2: 1-22.

Chablé-Santos, J. B., Chuma-Segura, L., \& Selem-Salas, C. (2011). Dermatemys mawii (Central American river turtle). Herpetological Review 42: 238.

Ernst, C.H. \& Barbour, R.W. (1989). Turtles of the World. Smithsonian Institution Press, Washington D. C., USA. xii + 313 pp. +8 pl.

IUCN (2019). IUCN Red List of Threatened Species. Most current version available online at http://www.iucnredlist. org.

Iverson, J. B. (1992). A Revised Checklist with Distribution Maps of the Turtles of the World. J.B. Iverson Publishers, Richmond, IN, USA. 363 pp.

Iverson, J. B. \& Mittermeier, R. A. (1980). Dermatemydidae, Dermatemys. Catalogue of American Amphibians and Reptiles 237: 1-4.
Lee, J. C. (1996). The Amphibians and Reptiles of the Yucatán Peninsula. Cornell University Press, Ithaca, NY, USA. xii + 500 pp. +41 pl.

Legler, J. M. \& Vogt, R. C. (2013). The Turtles of Mexico: Land and Freshwater Forms. University of California Press, Berkeley, CA, USA. 416 pp.

Moll, D. (1986). The distribution, status, and level of exploitation of the freshwater turtle Dermatemys mawii in Belize, Central America. Biological Conservation 35: 87-96.

Polisar, J. (1994). New legislation for the protection and management of Dermatemys mawii in Belize, Central America. Herpetological Review 25: 47-49.

Polisar, J. (1995). River turtle reproductive demography and exploitation patterns in Belize: Implications for management. Vida Silvestre Neotropical 4: 10-19.

Rainwater, T. R., Pop, T., Cal, O., Garel, A., Platt, S. G., \& Hudson, R. (2012). A recent countrywide status survey of the critically endangered Central American river turtle (Dermatemys mawii) in Belize. Chelonian Conservation and Biology 11: 97-107.

Slavenko, A., Itescu, Y., Ihlow, F., \& Meiri, S. (2015). Home is where the shell is: Predicting turtle home range sizes. Journal of Animal Ecology 85: 106-114.

Vogt, R. C., Gonzalez-Porter, G. P., \& Van Dijk, P. P. (2006). Dermatemys mawii (errata version published in 2016). The IUCN Red List of Threatened Species 2006: e.T6493A97409830. http://dx.doi.org/10.2305/IUCN. UK.2006.RLTS.T6493A12783921.en. Downloaded on 06 July 2019.

Vogt, R. C., Polisar, J. R., Moll, D., \& Gonzalez-Porter, G. (2011). Dermatemys mawii Gray 1847 - Central American river turtle, tortuga blanca, hickatee. In: Conservation Biology of Freshwater Turtles and Tortoises: A Compilation Project of the IUCN/SSC Tortoise and Freshwater Turtle Specialist Group. Chelonian Research Monographs No. 5, 058.1-058.12 pp. Rhodin, A.G.J., Pritchard, P.C.H., van Dijk, P.P, Saumure, R.A., Buhlmann, K.A., Iverson, J.B., \& Mittermeier, R.A. (Eds.). Chelonian Research Foundation.

Accepted: 5 August 2019 